\title{
Genotypic characterization of drug resistant Mycobacterium tuberculosis in Quebec, 2002-2012
}

\author{
Joanna Spinato ${ }^{1,4}$, Élyse Boivin², Émilie Bélanger-Trudelle ${ }^{2}$, Huguette Fauchon² ${ }^{2}$ Cécile Tremblay ${ }^{3}$ \\ and Hafid Soualhine $2^{2^{*}}$
}

\begin{abstract}
Background: The increasing emergence of drug-resistant tuberculosis presents a threat to the effective control of tuberculosis (TB). Rapid detection of drug-resistance is more important than ever to address this scourge. The purpose of this study was to genotypically characterize the first-line antitubercular drug-resistant isolates collected over 11 years in Quebec.

Results: The main mutations found in our resistant strains collection $(n=225)$ include: the S315T substitution in katG (50.2\%), the -15 C/T mutation in the inhA promoter (29\%); the S531L substitution in rpoB (43\%); the deletion 8 bp 446 / + R140S in pncA (72.9 \%); the M306I (35.7 \%) and M306V (21.4 \%) substitutions in embB. Ten of the mutations in katG and 4 mutations identified in pncA were previously undescribed.

Conclusion: Screening of mutations conferring resistance to first-line antituberculous drugs using DNA-sequencing approach seems to be feasible and would drastically shorten the time to determine the resistance profile compared to the proportion method.
\end{abstract}

Keywords: M. tuberculosis, Drug-resistance, rpoB, inhA, katG, pncA, embB

\section{Background}

In Canada, TB continues to affect Canadian populations disproportionately although the numbers of cases have been steadily decreasing over the past 30 years [1]. Drug resistance was found to be uncommon in Canadian-born TB patients. The highest rates of multidrug-resistant TB (MDR-TB) were from patients originating from the Eastern European region, and secondly, from the Western Pacific region. MDR-TB is defined resistance to at least isoniazid and rifampicin, whereas extensive drug resistant $\mathrm{TB}$ (XDR-TB) is an MDR-TB plus resistance to at least one injectable second-line drug and a fluoroquinolone. From the period of 1997 to 2008, there were 5 cases of extensively drug-resistant TB (XDR-TB), 177 cases of MDR-TB, and 1234 cases of first-line drug resistance not-MDR [2]. These five XDR-TB cases were reported

\footnotetext{
* Correspondence: hafid.soualhine@inspq.qc.ca

${ }^{2}$ Laboratoire de santé publique du Quebec, 20045 chemin Sainte-Marie,

Sainte-Anne de Bellevue, Quebec H9X 3R5, Canada

Full list of author information is available at the end of the article
}

in Ontario. The first XDR-TB case reported in the province of Quebec occurred in 2013 and concerned a patient emigrating from Eastern Europe (H. Soualhine, pers. comm.)

With the increase in the number of cases of drugresistant TB steadily emerging, and more of them becoming MDR or XDR-TB, a better knowledge of the molecular mechanisms of antitubercular drug-resistance have a significant impact on the improvement of rapid detection techniques and the diagnosis of drug resistance. In Quebec, primary identification of $M$. tuberculosis complex is based on Cobas TaqMan MTB assay (Roche Diagnostics, Rotkreuz, Switzerland). Rapid detection of rifampin resistance, based on Xpert MTB/RIF assay (Cepheid, Sunnyvale, CA, USA), is performed on selected specimens. Confirmatory identification at the species level is done using a PCRbased genomic deletion analysis of RD-regions [3] and drug susceptibility testing (DST) is performed using the phenotypic MGIT 960 method (Becton Dikinson, MD, USA).

First-line antituberculous drug resistance mechanisms are well studied. Several genes have been associated with 
drug resistance, namely $k a t G$ and $i n h A$, with isoniazid (INH) resistance; $r p o B$ with rifampicin (RMP) resistance; $e m b C A B$ with ethambutol (EMB) resistance; and $p n c A$ with pyrazinamide (PZA) resistance [4-7]. Line-probe assays (LPAs) including the (INNO-LiPA Rif.TB (Innogenetics, Zwijndrecht, Belgium) and the GenoType MTBDRplus (LPA), (HainLifeScience $\mathrm{GmbH}$, Nehren, Germany) and Xpert MTB/RIF (Cepheid) have been formally endorsed by the World Health Organization and are now in routine use in many TB laboratories [8]. The polymerase chain reaction sequencing-based approach is an accurate and rapid method for detection of drug-resistant $\mathrm{TB}$ and can identify several mutant alleles not previously associated with resistant organisms [4-7]. Recently, whole genome sequencing (WGS) of $M$. tuberculosis offers a powerful new approach to the identification of drug resistance. Furthermore, WGS of pathogens is becoming part of routine practice for establishing transmission and resistance patterns [9].

The aim of this study was to genotypically characterize resistant strains of $M$. tuberculosis circulating in Quebec, and to analyze the frequency of mutations conferring resistance to the four first-line antitubercular drugs using a DNA-sequencing approach.

\section{Methods}

M. tuberculosis isolates $(n=2248)$ were obtained from clinical specimens submitted for TB culture to the Public Health Laboratory in Quebec. Resistant isolates were selected based on drug resistance profiles $(n=225)$ to the four first-line drugs: INH, RMP, PZA, and EMB. Susceptible strains $(n=32)$ were included and two reference strains were selected: $M$. tuberculosis H37Ra reference strain ATCC 25177; and M. bovis BCG strain ATCC 35734 that is naturally resistant to PZA.

\section{Drug susceptibility testing (DST)}

All M. tuberculosis clinical isolates were tested for drug susceptibility using the BACTEC 460 instrument (Becton Dikinson, Sparks, MD, USA) from 2002 to 2005, the BACTEC MGIT 960 (Becton Dikinson) from 2010 to 2012, or by both instruments between 2006 and 2009. Critical drug concentrations used in the BACTEC 460 were INH $0.1 \mu \mathrm{g} / \mathrm{ml}$, RMP $2.0 \mu \mathrm{g} / \mathrm{ml}$, PZA $100 \mu \mathrm{g} / \mathrm{ml}$, and EMB $2.0 \mu \mathrm{g} / \mathrm{ml}$. For the BACTEC MGIT 960 instrument, critical concentrations used were INH 0.1 and $0.4 \mu \mathrm{g} / \mathrm{ml}$, RMP $1.0 \mu \mathrm{g} / \mathrm{ml}$, PZA $100 \mu \mathrm{g} / \mathrm{ml}$, and EMB $5.0 \mu \mathrm{g} / \mathrm{ml}[10]$.

The drug-resistant isolates were plated on LowensteinJensen slants at $37{ }^{\circ} \mathrm{C}$. DNA was extracted using the BioRobot M48 (Qiagen, Hilden, Germany) [11]: Isolates were prepared for DNA extraction by suspending representative colonies in tubes containing beads and lysis buffer. The samples were vortexed, heated at $100{ }^{\circ} \mathrm{C}$ for
$25 \mathrm{~min}$, cooled on ice for $2 \mathrm{~min}$, and then put in the MiniBeadbeater (Biospec Products, Inc. Bartlesville, OK, USA) for $2 \mathrm{~min}$. Finally the suspensions were centrifuged at $14000 \mathrm{rcf}$ for $2 \mathrm{~min}$, before being placed in the BioRobot, and the DNA was eluted into RNase-free water.

\section{PCR and DNA sequencing reactions}

Six pairs of oligonucleotide primers were designed to amplify regions of five genes associated with resistance to four antituberculosis drugs. PCR primers are listed in Table 1. DNA was amplified in a $50 \mu \mathrm{l}$ mixture containing PCR buffer, $200 \mu \mathrm{M}$ dNTP, $2 \mathrm{mM} \mathrm{MgCl} 2,0.5 \mu \mathrm{M}$ of each primer, 1 unit of AmpliTaq ${ }^{\circ}$ DNA polymerase (Applied Biosystems, Carlsbad, CA, USA) and $5 \mu \mathrm{L}$ of genomic DNA. The reaction was performed as follows: $5 \mathrm{~min}$ at $95{ }^{\circ} \mathrm{C}$, followed by 40 cycles of denaturation for $30 \mathrm{~s}$ at $95{ }^{\circ} \mathrm{C}$, annealing for $30 \mathrm{~s}$ at $60{ }^{\circ} \mathrm{C}$, and extension for $30 \mathrm{~s}$ at $72{ }^{\circ} \mathrm{C}$, with a final elongation step of $7 \mathrm{~min}$ at $72{ }^{\circ} \mathrm{C}$. The amplicons were purified using a MinElute 96 UF PCR purification plates (MinElute, Qiagen) and added as template for bidirectional DNA sequencing using an ABI PRISM BigDye terminator cycle sequencing kit v. 3.1 (Applied Biosystems, Woolston Warrington, UK). Reactions mixtures containing the forward or reverse primers were analysed with an ABI PRISM 3130xl genetic analyzer (Applied Biosystems). Bioinformatic analysis was done using the Lasergene (v. 10) software (DNAStar Inc. Madison, WI, USA). The obtained sequences were aligned in a multiple sequence alignments with the wild-type sequences of katG, inh $A$ promoter, rpoB, pncA, and embB.

Table 1 Primers used for drug resistant gene amplification

\begin{tabular}{|c|c|c|}
\hline Genes & Primers (Sequences $5^{\prime} \rightarrow 3^{\prime}$ ) & $\begin{array}{l}\text { Product } \\
\text { size (bp) }\end{array}$ \\
\hline \multirow[t]{2}{*}{ katG } & katG-F (5'-GACATTCGCGAGACGTTTCGG-3') & \multirow[t]{2}{*}{642} \\
\hline & katG-R (5'GCTCTTAAGGCTGGCAATCTCG-3') & \\
\hline \multirow[t]{2}{*}{$\operatorname{inh} A$} & inhA-F (5'-CTATATCTCCGGTGCGGTCA-3') & \multirow[t]{2}{*}{469} \\
\hline & inhA-R (5'-CTTGGCCATCGAAGCATAC-3') & \\
\hline \multirow[t]{2}{*}{ inhA-Prom } & inhA-Prom-1 (5'-TCCGTCATGGTCGAAGTGTG-3') & \multirow[t]{2}{*}{211} \\
\hline & inhA-Prom-2 (5'-GGTAACCAGGACTGAACGGG-3') & \\
\hline \multirow[t]{2}{*}{$r p o B$} & rpoB-F (5'-ACGGTCGGCGAGCTGATCC-3') & \multirow[t]{2}{*}{351} \\
\hline & $r p o B-R\left(5^{\prime}-C A G A C C G A T G T T G G G C C C C T-3^{\prime}\right)$ & \\
\hline \multirow[t]{2}{*}{ pncA } & pncA-F1 (5'-GGCGTCATGGACCCTATATC-3') & \multirow[t]{2}{*}{670} \\
\hline & pncA-R1 (5'-CAACAGTTCATCCCGGTTC-3') & \\
\hline \multirow[t]{2}{*}{$e m b B$} & embB-1 (5'- TGATATTCGGCTTCCTGCTC-3') & \multirow[t]{2}{*}{417} \\
\hline & embB-2 (5'- ACCGCTCGATCAGCACATAG-3') & \\
\hline \multirow[t]{4}{*}{$\Delta k a t G^{a}$} & katGD-1 (5'-CCGGTCAAGAAGAAGTACGG-3') & \multirow[t]{2}{*}{590} \\
\hline & katGD-2 (5'-CTCTTCGTCAGCTCCCACTC-3') & \\
\hline & katGD-5 (5'-GGGGAACATCAAAGTGTCCT-3') & \multirow[t]{2}{*}{400} \\
\hline & katGD-6 (5'-GATACCCATGTCGAGCAGGT-3') & \\
\hline
\end{tabular}

${ }^{\mathrm{a}}$ Deletion of katG 
Sensitivity and specificity were determined using the Diagnostic Effectiveness calculation from the Simple Interactive Statistical Analysis (SISA) software (Hilversum, The Netherlands) [12].

\section{$\Delta$ katG analysis}

Three INH-resistant clinical isolates repeatedly provided no amplication of katG gene fragment using the primer pairs previously listed. To confirm a katG gene deletion $(\Delta k a t G)$, amplification of other regions of this gene was investigated using different primer pairs. PCR was performed as described above with a second set of primers listed in Table 1, katGD-1 and katGD-2, designed to amplify a $590 \mathrm{bp}$ fragment upstream from that amplified with the $k a t G$ primers initially used. In addition, katGD-5 and katGD-6 were used to amplify a 400 bp region of the katG gene that overlaps with the region targeted by the katG-F and $k a t G-R$ primers.

\section{Catalase-peroxidase assays}

A semi-quantitative catalase assay was performed in duplicate as previously described [13], on three $\Delta k a t G$ strains and five selected INH-resistant strains with undescribed $k a t G$ gene mutations. Controls included the reference strains of M. tuberculosis, M. avium ATCC 700898 for low catalase activity, and $M$. gordonae ATCC35756 for high catalase activity.

\section{Results}

The province of Quebec has reported a total of 2248 strains of $M$. tuberculosis between 2002 and 2012, of which 225 were resistant (Fig. 1). Drug resistant TB in
Quebec is mainly associated with INH and PZA monoresistance. Among the 225 phenotypically resistant isolates selected, 20 were MDR-TB. Mono-resistance patterns include 155 to INH, 3 to RMP and 41 to PZA. Six isolates were resistant to at least two first-line drugs but were not MDR. In total, 180 isolates were resistant to INH, 23 to RMP, 48 to PZA, and 14 isolates were resistant to EMB.

\section{katG gene}

Out of 180 phenotypically INH-resistant isolates, 110 had a mutation in the targeted region of katG (61 \%) (Table 2) and 3 isolates were $\Delta k a t G$.

A total of 10 mutations in katG gene were novel and found in INH monoresistant strains; five undescribed substitutions occurred alone (V284G; P375R; Y413C; del G1284 and D448N) and five substitutions occurred in combination with a mutation known to confer INHresistance, among them P280S and S303A occurred with $-15 \mathrm{C} / \mathrm{T}$ in inhA promoter while D387H; V450S; and G451S occurred with S315T in katG. The main mutation in katG (50.2 \%) was the AGC/ACC (S315T). In $8.8 \%$ of the S315T mutants, inhA promoter mutations were also identified. Three INH-resistant isolates demonstrated no amplification of the katG gene fragment using the primer pairs katG-F/katG-R, katGD-1/katGD-2 and katGD-5/katGD-6. No catalase activity was observed by the semi-quantitative catalase assay on those three clinical isolates compared to the control strains of M. tuberculosis, the weak catalase producer $M$. avium and the strong producer, $M$. gordonae, which showed an average of $28 \mathrm{~mm}$, $9 \mathrm{~mm}$ and $57 \mathrm{~mm}$ of oxygen bubble production respectively. The katG mutated strains (V284G; P375R; Y413C;

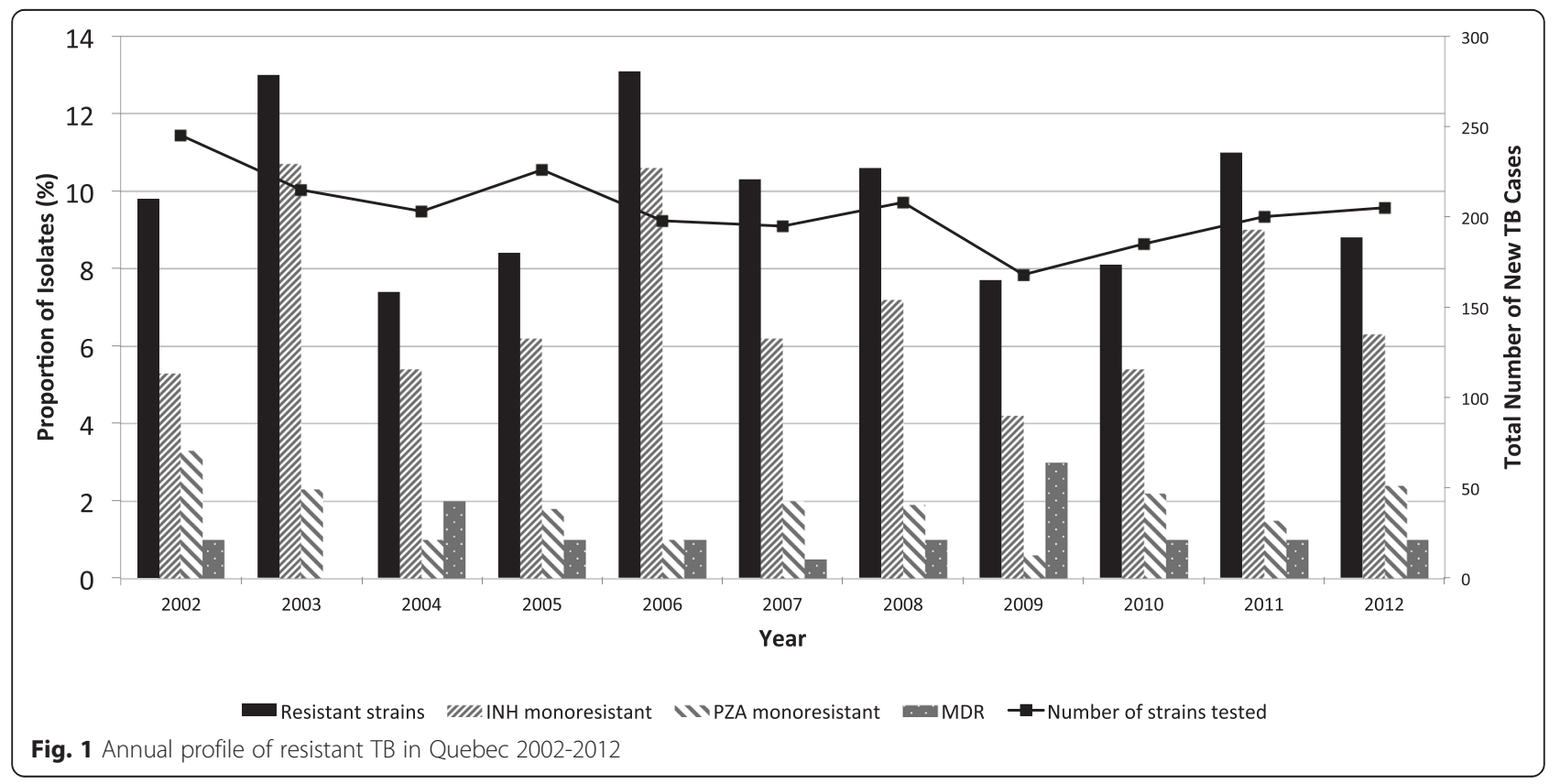


Table 2 INH-Resistance conferring mutations in $180 \mathrm{INH}-\mathrm{R}(85 \%)$ and $32 \mathrm{INH}-\mathrm{S}$ (15\%) isolates

\begin{tabular}{|c|c|c|c|c|}
\hline \multirow{2}{*}{$\frac{\text { Drug resistance }}{\mathrm{INH}^{\mathrm{R}}}$} & \multirow[t]{2}{*}{ Genes } & \multirow{2}{*}{$\frac{\text { No. of isolates }}{180}$} & \multicolumn{2}{|l|}{ Changes } \\
\hline & & & Nucleotides & Amino acid \\
\hline & & 3 & $\Delta k a t G$ & \\
\hline & & & Single mutation & \\
\hline & & 1 & GTC/GGC & $\mathrm{V} 284 \mathrm{G}^{\mathrm{a}}$ \\
\hline & & 1 & AGC/AAC & S315N \\
\hline & & 1 & AGC/GGC & S315G \\
\hline & & 78 & AGC/ACC & S315T \\
\hline & katG & 1 & $\mathrm{CCG} / \mathrm{CGG}$ & $P 375 R^{a}$ \\
\hline & & 1 & TAC/TGC & $Y 413 C^{a}$ \\
\hline & & 1 & del G1284 & frameshift $^{a}$ \\
\hline & & 1 & TGG/TCG & W438S \\
\hline & & 1 & GAC/AAC & $\mathrm{D} 448 \mathrm{~N}^{\mathrm{a}}$ \\
\hline & & & Multiple mutations & \\
\hline & & 1 & AGC/ACC, TGA/TAA & S315T, 343Stop \\
\hline & & 1 & AGC/ACC, GAT/CAT & $\mathrm{S} 315 \mathrm{~T}, \mathrm{D} 387 \mathrm{H}^{\mathrm{b}}$ \\
\hline & & 1 & AGC/ACC, GTC/GAC & S315T, V450D ${ }^{b}$ \\
\hline & & 1 & AGC/ACC, GGC/AGC & S315T, G451S ${ }^{b}$ \\
\hline & & & Single mutations & \\
\hline & $\operatorname{inh} A$ & 3 & $\mathrm{TCG} / \mathrm{GCG}$ & S94A \\
\hline & & 1 & $-8 \mathrm{~T} / \mathrm{C}$ & None \\
\hline & $\operatorname{inh} A-p$ & 37 & $-15 \mathrm{C} / \mathrm{T}$ & None \\
\hline & & 3 & $-17 \mathrm{G} / \mathrm{T}$ & None \\
\hline & & & Multiple mutations & \\
\hline & $\operatorname{inh} A-p$ & 1 & $-15 \mathrm{C} / \mathrm{T},-47 \mathrm{G} / \mathrm{T}$ & None \\
\hline & $\operatorname{inh} A$, inhA-p & 1 & GGA/GGC, $-15 C / T$ & G3G, None \\
\hline & & 2 & ATC/ACC, $-15 C / T$ & I21T, None \\
\hline & & 3 & ATC/GTC, $-15 C / T$ & I21V, None \\
\hline & katG, inhA & 1 & AGC/ACC, GGA/GGC & S315T, G3G \\
\hline & & 3 & GAA/GAC, $-15 C / T$ & E261D, None \\
\hline & $k a t G$, inhA-p & 1 & $\mathrm{CCG} / \mathrm{TCG},-15 \mathrm{C} / \mathrm{T}$ & P280S ${ }^{b}$, None \\
\hline & & 1 & TCG/GCG, $-15 C / T$ & S303A $A^{\mathrm{b}}$, None \\
\hline & & 1 & $\mathrm{ACC} / \mathrm{GCC},-15 \mathrm{C} / \mathrm{T}$ & T314A, None \\
\hline & & 1 & AGC/AAC, $-47 G / C$ & S315N, None \\
\hline & & 2 & AGC/ACC, -8 T/A & S315T, None \\
\hline & & 3 & AGC/ACC, $-8 \mathrm{~T} / \mathrm{C}$ & S315T, None \\
\hline & & 2 & AGC/AAC, $-15 C / T$ & S315T, None \\
\hline & & 1 & AGC/AAC, $-102 \mathrm{G} / \mathrm{A}$ & S315T, None \\
\hline & & 1 & ACT/ATT, $-15 C / T$ & T3081, None \\
\hline & katG, inhA, inhA-p & 19 & WT & None \\
\hline $\mathrm{INH}^{\mathrm{S}}$ & $k a t G, \operatorname{inh} A, \operatorname{inh} A-p$ & 32 & WT & None \\
\hline
\end{tabular}

andescribed mutations that occur alone; ${ }^{b}$ undescribed mutations that occur in combination with another resistance-associated mutation; inhA-p, inhA promoter, del, deletion; WT wild-type sequence, $R$ resistant, $S$ susceptible 
del G1284 and D448N) identified in our study, have shown a catalase activity of $19 \mathrm{~mm}, 21 \mathrm{~mm}, 38 \mathrm{~mm}$, $11 \mathrm{~mm}$ and $27 \mathrm{~mm}$ respectively.

\section{inhA gene}

Eight out of the $180 \mathrm{INH}$-resistant isolates (4.4\%) contained a single point mutation in the $i n h A$ gene. Three isolates had an I21V substitution, 2 had an I21T substitution, and 3 had a S94A substitution. The substitutions at codon 21 always occurred in combination with the $-15 \mathrm{C} / \mathrm{T}$ mutation in the inhA promoter.

\section{inhA promoter}

Isolates with a mutation in the $i n h A$ promoter made up a total of $36 \%$ of INH-resistances. The most commonly encountered mutation was $-15 \mathrm{C} / \mathrm{T}$ (29\%), followed by mutations at position -8 (3.9\%). The mutations at -47 and -102 always occurred in combination with the -15 C/T inhA-promoter mutation, the S315T, or the S315N substitution in $k a t G$, which are mutations known to confer INH-resistance.

\section{rpoB}

All RMP-resistant isolates contained a mutation in the targeted region of the rpoB gene (Table 3): One had an insertion of F514 (TTC), 18 had a single point mutation, and 4 contained two point mutations. All mutations occurred within the RMP resistance determining region (RRDR) except T480I (ACC/ATG); this mutation occurred in combination with the S531L substitution. The most common mutation observed in $r p o B$ was at codon 531, such as the S351L substitution, which was found in $47.8 \%$ of the isolates. Substitutions at codon 526 were found in $26 \%$ of isolates. Two L511R substitutions occurred in combination with D516Y.

\section{pncA}

Forty-five out of 48 PZA-resistant isolates had a mutation in the $p n c A$ gene or in the $p n c A$ promoter $(93.7 \%)$. As shown in Table 3, 35 PZA-monoresistant isolates had a mutation, identified only in Quebec, which consist of a deletion of $8 \mathrm{bp}$ at position 446 (frameshift) in combination with the R140S substitution (CGC/AGC). Two PZA-resistant strains harboured no mutation in the $p n c A$ gene and one PZA-resistant strain contained only a silent mutation, A46A (GCA/GCG).

\section{$e m b B$}

Thirteen of 14 EMB-resistant isolates had a mutation in the $e m b B$ gene $(92.8 \%)$. The most commonly found substitution occurred at codon 306 (57 \%). Other substitutions include Y319S, D328Y, D354A, G406S, and E378A. The isolate with the E378A substitution also had a substitution in codon 306 and a silent mutation in codon 355 .

\section{Mutations and MDR-TB}

Twenty isolates were MDR-TB as defined by resistance to both INH and RMP. The most common mutation combination seen in the MDR-TB isolates was in rpoB531 and katG315 (40\%), followed by rpoB526 and katG315 (15\%), and $i n h A$ promoter - 15 with rpoB531 (15\%) among others (Table 4).

\section{Discussion}

Phenotypic DST is performed using the BACTEC MGIT 960 system. While this method is termed the gold standard for determining drug susceptibility profiles of $M$. tuberculosis isolates, it can take two weeks before results are available. Limitations of phenotypic methods include the uncertain reliability of conventional breakpoints, decreased accuracy in cultures mixed with other mycobacteria, and the possibility of reduced fitness and growth of mutant organisms, which may require a higher inoculum to increase test sensitivity. Further, DST to PZA can be hampered by false-positive results [14].

In our study, DNA sequencing is applicable for the detection of INH-resistant isolates with $60.8 \%$ sensitivity (95 \% CI, 51.7 to 69.8 ) and $100 \%$ specificity for the katG gene and with $35.9 \%$ sensitivity (95\% CI, 27 to 44.8) and $100 \%$ specificity for the $i n h A$ promoter. Combined the two tests have $85.1 \%$ sensitivity ( $95 \% \mathrm{CI}, 78.5$ to 91.7) and $100 \%$ specificity.

Ten mutations identified in the katG gene of the INHresistant isolates were undescribed according to our knowledge. Five substitutions occurred in combination with resistance-associated mutations, meaning that the resistance observed with these isolates can be attributed to the well-established resistance-conferring mutations; these undescribed mutations could also be associated with fitness cost of INH resistance [15]. The remaining five undescribed substitutions that occurred alone (V284G, P375R, Y413C, del G 1284, and D448N) require further analysis. Five strains harboring these mutations showed catalase activity. Among them, 3 strains (V284G, P375R, and del G 1284) showed a reduced catalase activity compared to the control strains.

In our isolates, the S315T substitution accounted for $50.2 \%$ of the katG gene mutations. This particular substitution has also been reported to occur more frequently in MDR-TB isolates, presumably because it provides INH resistance with the retention of virulence [16]. This would allow the S315T mutated strains to persist in the intracellular environment and possibly become resistant to additional antitubercular drugs. In three strains of our collection, the deletion of katG resulted in no KatG enzymatic activity, and therefore, INH cannot be converted into its active form. It was shown that when KatG activity has been completely lost, $\operatorname{ahpC}$ promoter mutations are usually 
Table 3 Characteristic of mutations found in resistant isolates to RMP $(n=23)$, PZA $(n=48)$ or EMB $(n=14)$ compared to susceptible strains $(n=32)$

\begin{tabular}{|c|c|c|c|c|}
\hline Drug resistance & Genes & No. of isolates & Changes & \\
\hline \multirow[t]{12}{*}{$\overline{\mathrm{RMP}^{\mathrm{R}}}$} & $r p o B$ & 23 & Nucleotides & Amino acid \\
\hline & & & Single mutations & \\
\hline & & 1 & TTC514 & Ins F514 \\
\hline & & 2 & GAC/GTC & D516V \\
\hline & & 4 & CAC/GAC & H526D \\
\hline & & 2 & CAC/CGC & H526R \\
\hline & & 8 & TCG/TTG & S531L \\
\hline & & 1 & $\mathrm{TCG} / \mathrm{TT}$ & S531F \\
\hline & & 1 & $\mathrm{CTG} / \mathrm{CCG}$ & L533P \\
\hline & & & Multiple mutations & \\
\hline & & 2 & $\mathrm{CTG} / \mathrm{CGG}, \mathrm{GAC} / \mathrm{TAC}$ & L511R, D516Y \\
\hline & & 2 & $\mathrm{TCG} / \mathrm{TTG}, \mathrm{ACC} / \mathrm{ATG}$ & S531L, T480I \\
\hline $\mathrm{RMP}^{\mathrm{S}}$ & $r p o B$ & 32 & WT & None \\
\hline \multirow[t]{15}{*}{$P Z A^{R}$} & pncA & 48 & & \\
\hline & & & Single mutations & \\
\hline & & 1 & $-11 A / G$ & None \\
\hline & & 1 & CTG/CCG & L27P \\
\hline & & 1 & Del G164 & Frameshift $^{a}$ \\
\hline & & 2 & ATC/AGC & I90S \\
\hline & & 1 & GCG/CCG & $\mathrm{A} 92 \mathrm{P}^{\mathrm{a}}$ \\
\hline & & 1 & Del 9 bp 380 & Del $D, E, V^{a}$ \\
\hline & & 1 & $\mathrm{ACC} / \mathrm{CCC}$ & T135P \\
\hline & & 1 & Ins AT 447 & Frameshift $^{\mathrm{a}}$ \\
\hline & & 1 & $\mathrm{ACC} / \mathrm{CCC}$ & T168P \\
\hline & & & Multiple mutations & \\
\hline & & 35 & Del8 bp446, CGC/AGC & Frameshift, R140S \\
\hline & & 1 & GCA/GCG & $\mathrm{A} 46 \mathrm{~A}$ \\
\hline & & 2 & WT & None \\
\hline $\mathrm{PZA}^{\mathrm{S}}$ & pncA & 32 & WT & None \\
\hline \multirow[t]{11}{*}{$\mathrm{EMB}^{\mathrm{R}}$} & $e m b B$ & 14 & & \\
\hline & & & Single mutations & \\
\hline & & 4 & ATG/ATA & M306। \\
\hline & & 3 & ATG/GTG & M306V \\
\hline & & 2 & TAT/TCT & Y319S \\
\hline & & 1 & GAT/TAT & D328Y \\
\hline & & 1 & GAC/GCC & D354A \\
\hline & & 1 & GGC/AGC & G406S \\
\hline & & & Multiple mutations & \\
\hline & & 1 & ATG/ATA, CTG/CTA, GAG/GCG & M306I, L355L, E387A \\
\hline & & 1 & WT & None \\
\hline$E M B^{S}$ & $e m b B$ & 32 & WT & None \\
\hline
\end{tabular}


Table 4 Characteristic of mutations found in 20 MDR isolates

\begin{tabular}{|c|c|c|c|c|c|c|}
\hline \multirow[t]{2}{*}{ No. of MDR isolates } & \multicolumn{2}{|l|}{ RMP } & \multicolumn{2}{|l|}{$\mathrm{INH}$} & \multirow{2}{*}{$\begin{array}{l}\text { EMB } \\
\text { embB }\end{array}$} & \multirow{2}{*}{$\begin{array}{l}\text { PZA } \\
p n c A\end{array}$} \\
\hline & $r p o B$ & katG & $\operatorname{inh} A$ & $\operatorname{inh} A-p$ & & \\
\hline 1 & L511R, D516Y & S315T & & & & \\
\hline 1 & L511R, D516Y & S315T & & & & del 9 bp 380 (del D,E,V) \\
\hline 1 & Ins F514 & S315T & & $\mathrm{T}-8 \mathrm{~A}$ & & T168P \\
\hline 1 & D516V & S315T & & $\mathrm{T}-8 \mathrm{~A}$ & G406S & InsAT 447 \\
\hline 1 & D516V & E261D & & $C-15 T$ & & \\
\hline 1 & H526D & S315T & & & & \\
\hline 1 & H526D & S315T & & & M306l & \\
\hline 1 & H526D & S315T & & & D328Y & \\
\hline 1 & S531F & S315T & & & & \\
\hline 2 & S531L & S315T & & & & \\
\hline 1 & S531L & S315T & & $C-15 T$ & Y319S & \\
\hline 2 & S531L & & & $C-15 T$ & & \\
\hline 1 & S531L & & $121 \mathrm{~T}$ & $C-15 T$ & M306l & \\
\hline 1 & S531L & S315T & & & D354A & T135P \\
\hline 1 & S531L & S315T & & $\mathrm{T}-8 \mathrm{C}$ & & $A-11 G$ \\
\hline 2 & S531L, T480I & S315T & & & M306V & \\
\hline 1 & L533P & S315T & & & M306l & L27P \\
\hline
\end{tabular}

inhA-p inhA promoter, del deletion, Ins insertion

found. The $a h p C$ gene encodes an enzyme involved in antioxidant defense, as does the $k a t G$ gene product [13].

inh $A$ promoter mutations made up $36 \%$ of the INHresistant isolates. Two rarely reported mutations were also identified at positions -47 and -102 . As these two mutations always occur in combination with the S315T substitution in $k a t G$ as previously found, their consequences are unknown at the present time.

In contrast, there were $19 \mathrm{INH}$-resistant isolates that did not have any mutations in $k a t G$, inhA, or the inhA promoter; other mechanisms of resistance could be at play. Mutations in other genes such as $\operatorname{ahpC}$, kasA, $n d h$, and $m s h A$ have also been reported [17], in addition to efflux-related mechanisms $[18,19]$.

We have identified rpoB mutations in $100 \%$ of the RMP-resistant isolates. Previous studies indicate that mutations at codons 531, 526, and 516 make up the majority of RMP-resistance mutations reported [20]. All mutations identified in the $r p o B$ gene occurred within the RRDR except one substitution, T480I, which occurred outside of this core region. Both isolates that had the T480I substitution also had S531L substitution; it is unclear whether the T480I substitution is involved in RMP resistance [21]. One insertion of F514 was identified in our collection. This insertion was also reported in a strain isolated from the same patient in Ontario [22].

RMP mono-resistance is rarely reported [20]. In this study $87 \%$ of the RMP-resistant isolates were also resistant to INH, making them MDR-TB. The molecular tests could therefore be used to identify the majority of MDR-TB cases. The automated PCR test utilizing the GeneXpert platform, which can accurately detect TB as well as RMP resistance within $2 \mathrm{~h}$, is useful for detecting MDR-TB [8]. As with the line probe assay, not all mutations will be identified in the $r p o B$ gene that confers RMP resistance. Novel mutations cannot be identified, and other mutations cannot be detected with these assays [23-25].

Mutations in the $p n c A$ gene and promoter accounted for $93.8 \%$ of PZA resistance. DNA sequencing had detected PZA resistance with a sensitivity of $93.8 \%(95 \%$ CI, 85 to 100) and specificity of $100 \%$. Among the Canadian-born population in Quebec, a high proportion of TB isolates are monopyrazinamide-resistant comparing to the other provinces $[2,26]$. In the absence of a recognized outbreak, it was hypothesized that these isolates most likely represented reactivation of an old endemic strain [26]. The most common mutation seen in the province was a deletion of $8 \mathrm{bp}$ at position 446 combined with a R140S substitution (72.9\%). Previous studies have shown that strains carrying this mutation are related [26, 27] and suggested that the clonal PZAresistant strains carrying this mutation are actively being transmitted, rather than acquired resistance individually in the patient via the selective pressures of drug exposure [26].

Four novel mutations found in our collection consisted of a deletion (G at position 164) in INH and PZA-resistant strain; an insertion (AT at position 447) and a deletion of residues $\mathrm{D}, \mathrm{E}$, and $\mathrm{V}$ at position 380 found in $2 \mathrm{MDR}$ 
strains, and the A92P substitution in one monoresistant strain. There were 3 PZA-resistant isolates that did not have a mutation in the $p n c A$ gene; this cannot rule out a false resistant result by the phenotypic method [14]. Furthermore, not all PZA-resistant $M$. tuberculosis isolates have mutations in this gene [28], which is suggestive of other mechanisms of resistance. For instance, mutations in the rpsA gene, encoding ribosomal protein S1, have been described as a mechanism for PZA resistance. A silent mutation of A46A was identified in one isolate. According to Somoskovi et al., this SNP is reported to serve as a marker of $M$. canettii, which is naturally resistant to PZA, but not as a result of $p n c A$ mutations [29]. This strain, which was probably misidentified as $M$. tuberculosis, since it also contains the RD9 region, showed smooth colonies, characteristic of $M$. canettii [3]. Other mechanisms reported to cause PZA resistance in $M$. tuberculosis, $M$. canettii, and M. bovis include: altered PZA uptake and/or pyrazinoic acid efflux [30].

EMB-resistance conferring mutations were identified in 13 out of 14 EMB-resistant isolates (sensitivity of $92.8 \%$ (95\% CI, 75.6 to 100) and a specificity of $100 \%$ ). Fiftyseven percent of identified substitutions occurred at codon 306 which is the most common site reported for changes associated with EMB resistance [31]. A substitution, E378A, was found in one EMB-resistant clinical isolate in our collection. The same mutation was also identified in one EMB-susceptible clinical isolate, and in the EMB-susceptible control, M. bovis BCG TMC1011 as was previously reported upon whole genome sequencing [32]. Our EMB-resistant isolate also contained the M306I substitution. The substitution caused by E378A in the BCG and clinical isolate are not associated with EMBresistance, and are reported as polymorphism that is not resistance related.

One EMB-resistant isolate did not have mutations in the $e m b B$ gene, which may indicate other mechanisms of EMB resistance do exist [33]. An efflux pump mechanism has been associated with resistance to EMB [18], and occasionally resistance-conferring mutations have also been reported in $e m b C$ [34].

\section{Conclusion}

DNA sequencing was able to detect mutations in the targeted genes: katG (62\%); inhA promoter (36 \%); inhA gene (4.4\%); katG and inhA promoter together (89.5\%). From RMP, PZA, and EMB, $100 \%, 93.7 \%$, and $92.8 \%$ of resistant strains showed a mutation in rpoB, pncA, and $e m b B$, respectively. Comparing to the phenotypic methd, DNA sequencing of targeting genomic regions associated with drug resistance would drastically shorten time to resistance profile determination in clinical isolates collected in the region.
It is of great importance to note that the absence of a mutation does not imply drug susceptibility; therefore, it is essential that molecular methods must always be compared to the gold standard method.

\begin{abstract}
Abbreviations
$\mathrm{Cl}$, Confidence Interval; DST, drug susceptibility testing; EMB, ethambutol; INH, isoniazid; MDR-TB, multidrug-resistant tuberculosis; PZA, pyrazinamide; RMP, rifampin; RRDR, rifampin resistance determining region; SISA, simple interactive statistical analysis; XDR-TB, extensively drug-resistant tuberculosis; $\Delta \mathrm{katG}$, katG gene deletion.
\end{abstract}

\section{Acknowledgments \\ The authors would like to thank Florence Doualla-Bell, for reviewing this paper; Isabelle Noel, Lise Côté and Marc-Christian Domingo for their technical assistance.}

\section{Funding}

This work was supported by the Institut national de santé publique du Quebec - LSPQ- Sainte-Anne-de-Bellevue, Quebec, Canada.

\section{Availability of data and materials}

Data supporting our findings are contained within the manuscript and can be shared.

\section{Authors' contributions}

JS and HS participated in the design, data collection, and analysis and manuscript development. JS, EB, EBT and HF participated in technical work, data analysis, and interpretation of the data. CT, JS and HS participated in interpretation of the data, reviewed the manuscript. All authors read and approved the final manuscript.

\section{Authors' information}

Joanna Spinato completed this work at the LSPQ as M.Sc. student in the Institute of Parasitology at McGill University (Montreal, Quebec). She is currently the Occupational Health and Safety Officer at the Public Health

Ontario Laboratory in Toronto, ON, Canada.

\section{Competing interests}

The authors declare that they have no competing interests.

\section{Consent for publication}

Not applicable.

\section{Ethics approval and consent to participate}

The M. tuberculosis isolates were selected from the bacterial collection maintained at the mycobacteriology laboratory at the Laboratoire de santé publique du Quebec. The study was approved by the Institut national de santé publique du Quebec Research Ethical Committee - Sainte-Anne-de-Bellevue, Quebec, Canada.

\section{Author details}

${ }^{1}$ McGill University, Montreal, Quebec, Canada. ${ }^{2}$ Laboratoire de santé publique du Quebec, 20045 chemin Sainte-Marie, Sainte-Anne de Bellevue, Quebec H9X 3R5, Canada. ${ }^{3}$ Université de Montreal, Montreal, Quebec, Canada. ${ }^{4}$ Present address: Public Health Ontario Laboratory, Toronto, Ontario M5G $1 \mathrm{M} 1$, Canada

Received: 1 February 2016 Accepted: 22 July 2016

Published online: 26 July 2016

\section{References}

1. Public Health Agency of Canada. The Chief Public Health Officer's Report on the State of Public Health in Canada, 2013. Infectious Disease - The Neverending Threat. 2013. http://www.phac-aspc.gc.ca/cphorsphc-respcacsp/ 2013/tuber-eng.php. Accessed 16 Dec 2013.

2. Minion J, Gallant V, Wolfe J, Jamieson F, Long R. Multidrug and extensively drug-resistant tuberculosis in Canada 1997-2008: Demographic and disease characteristics. PLoS One. 2013;8(1):e53466. doi:10.1371/journal.pone.0053466.

3. Mostowy S, Cousins D, Brinkman J, Aranaz A, Behr MA. Genomic deletions suggest a phylogeny for the Mycobacterium tuberculosis complex. J Infect Dis. 2002;186(1):74-80. 
4. Zhang Y, Heym B, Allen B, Young D, Cole S. The catalase-peroxidase gene and isoniazid resistance of Mycobacterium tuberculosis. Nature. 1992;358(6387):591-3.

5. Banerjee A, Dubnau E, Quemard A, Balasubramanian V, Um KS, Wilson T, Collins D, de Lisle G, Jacobs Jr WR. inhA, a gene encoding a target for isoniazid and ethionamide in Mycobacterium tuberculosis. Science. 1994;263:227-30.

6. Telenti A, Imboden P, Marchesi F, Lowrie D, Cole S, Colston MJ, Matter L Schopfer K, Bodmer T. Detection of rifampicin-resistance mutations in Mycobacterium tuberculosis. Lancet. 1993;341:647-50.

7. Sreevatsan S, Pan X, Zhang Y, Kreiswirth BN, Musser JM. Mutations associated with pyrazinamide resistance in pncA of Mycobacterium tuberculosis complex organisms. Antimicrob Agents Chemother. 1997;41(3):636-40.

8. World Health Organization (WHO). Automated real-time nucleic acid amplification technology for rapid and simultaneous detection of tuberculosis and rifampin resistance: Xpert MTB/RIF System Policy Statement. Geneva, Switzerland. 2011: http://apps.who.int/iris/handle/10665/112472 Accessed 22 July 2016.

9. Williams OM, Abeel T, Casali N, Cohen k, Pym AS, Mungall SB, Desjardins CA Banerjee A, Drobniewski F, Earl AM, Graham S., Cooke GS. Fatal nosocomial MDR TB identified through routine genetic analysis and whole-genome sequencing. Emerg Infect Dis. 2015; doi:10.3201/eid2106.141903.

10. Becton Dickinson and Company. BD BACTEC MGIT 960 SIRE Kits for the antimycobacterial susceptiblity testing of Mycobacterium tuberculosis. Sparks: BD; 2015 (Publication number 8008200(02)) http://www.bd.com/ ds/technicalCenter/inserts/8008200(02).pdf\#page=1\&view=Fit. Accessed 21 July 2016

11. Qiagen. MagAttract DNA Mini M48 Handbook. Hilden: Qiagen; 2012.

12. Uitenbroek DC. SISA-Binomial. 1997. http://www.quantitativeskills.com/sisa/ distributions/binomial.htm. Accessed 5 Dec 2013.

13. Ramaswamy SV, Reich R, Dou SJ, Jasperse L, Pan X, Wanger A, Quitugua T, Graviss EA. Single nucleotide polymorphisms in genes associated with isoniazid resistance in Mycobacterium tuberculosis. Antimicrob Agents Chemother. 2003:47(4):1241-50.

14. Chedore P, Bertucci L, Wolfe J, Sharma M, Jamieson F. Potential for erroneous results indicating resistance when using the Bactec MGIT 960 system for testing susceptibility of Mycobacterium tuberculosis to pyrazinamide. J Clin Microbiol. 2010;48(1):300-1.

15. Borrell S, Gagneux S. Infectiousness, reproductive fitness and evolution of drugresistant Mycobacterium tuberculosis. Int J Tuberc Lung Dis. 2009;13(12):1456-66.

16. Hazbón MH, Brimacombe M, del Valle MB, Cavatore M, Guerrero Ml, VarmaBasil M, Billman-Jacobe H, Lavender C, Fyfe J, García-García L, León Cl, Bose M, Chaves F, Murray M, Eisenach KD, Sifuentes-Osornio J, Cave MD, Ponce de León A, Alland D. Population genetics study of isoniazid resistance mutations and evolution of multidrug-resistant Mycobacterium tuberculosis. Antimicrob Agents Chemother. 2006;50:2640-9.

17. Johnson R, Streicher EM, Louw GE, Warren RM, van Helden PD, Victor TC. Drug resistance in Mycobacterium tuberculosis. Curr Issues Mol Biol. 2006;8(2):97-111.

18. Colangeli R, Helb D, Sridharan S, Sun J, Varma Basil M, Hazbón MH, Harbacheuski R, Megjugorac NJ, Jacobs Jr WR, Holzenburg A, Sacchettini JC, Alland D. The Mycobacterium tuberculosis iniA gene is essential for activity of an efflux pump that confers drug tolerance to both isoniazid and ethambutol. Mol Microbiol. 2005;55:1829-40.

19. Jiang $X$, Zhang W, Zhang Y, Gao F, Lu C, Zhang X, Wang H. Assessment of efflux pump gene expression in a clinical isolate Mycobacterium tuberculosis by real-time reverse transcription PCR. Microb Drug Resist. 2008;14:7-11.

20. Pang $Y$, Lu J, Wang $Y$, Song $Y$, Wang S, Zhao Y. Study of the rifampin monoresistance mechanism in Mycobacterium tuberculosis. Antimicrob Agents Chemother. 2013;57:893-900.

21. Williams DL, Spring L, Collins L, Miller LP, Heifets LB, Gangadharam PR, Gillis TP. Contribution of rpoB mutations to development of rifamycin cross-resistance in Mycobacterium tuberculosis. Antimicrob Agents Chemother. 1998;42(7):1853-7.

22. Bolotin S, Alexander DC, Chedore P, Drews SJ, Jamieson F. Molecular characterization of drug-resistant Mycobacterium tuberculosis isolates from Ontario, Canada. J Antimicrobial Chemother. 2009;64:263-6.

23. Perdigão J, Macedo R, João I, Fernandes E, Brum L, Portugal I. Multidrug-resistant tuberculosis in Lisbon, Portugal: a molecular epidemiological perspective. Microb Drug Resist. 2008:14(2):133-43.

24. Kalokhe AS, Shafiq M, Lee JC, Metchock B, Posey JE, Ray SM, Anderson A, Wang YF, Nguyen ML. Discordance in Mycobacterium tuberculosis rifampin susceptibility. Emerg Infect Dis. 2012;18:537.
25. McAlister AJ, Driscoll J, Metchock B. DNA sequencing for confirmation of rifampin resistance detected by Cepheid Xpert MTB/RIF assay. J Clin Microbiol. 2015;53(5):1752-3

26. Nguyen D, Brassard P, Westley J, Thibert L, Proulx M, Henry K, Schwartzman K, Menzies D, Behr MA. Widespread pyrazinamide-resistant Mycobacterium tuberculosis family in a low-incidence setting. J Clin Microbiol. 2003:41:2878-83.

27. Cheng S, Thibert L, Sanchez T, Heifets L, Zhang Y. pncA mutations as a major mechanism of pyrazinamide resistance in Mycobacterium tuberculosis: spread of a monoresistant strain in Quebec, Canada. Antimicrob Agents Chemother. 2000;44:528-32.

28. Simons SO, van Ingen J, van der Laan T, Mulder A, Dekhuiizen PN, Boeree MJ, van Soolingen D. Validation of pncA gene sequencing in combination with the mycobacterial growth indicator tube method to test susceptibility of Mycobacterium tuberculosis to pyrazinamide. J Clin Microbiol. 2012;50:428-34.

29. Somoskovi A, Dormandy J, Parsons LM, Kaswa M, Goh KS, Rastogi N, Salfinger M. Sequencing of the pncA gene in members of the Mycobacterium tuberculosis complex has important diagnostic applications: identification of a species-specific pncA mutation in "Mycobacterium canetti" and the reliable and rapid predictor of pyrazinamide resistance. J Clin Microbiol. 2007;45:595-9.

30. Zhang Y, Scorpio A, Nikaido H, Sun Z. Role of acid pH and deficient efflux of pyrazinoic acid in unique susceptibility of Mycobacterium tuberculosis to pyrazinamide. J Bacteriol. 1999:181(7):2044-9.

31. Plinke C, Rüsch-Gerdes S, Niemann S. Significance of mutations in embB codon 306 for prediction of ethambutol resistance in clinical Mycobacterium tuberculosis isolates. Antimicrob Agents Chemother. 2006;50:1900-2.

32. Sekiguchi J, Miyoshi-Akiyama T, Augustynowicz-Kopeć E, Zwolska Z, Kirikae F, Toyota E, Kobayashi I, Morita K, Kudo K, Kato S, Kuratsuji T, Mori T, Kirikae T. Detection of multidrug resistance in Mycobacterium tuberculosis. J Clin Microbiol. 2007;45:179-92.

33. Alcaide F, Pfyffer GE, Telenti A. Role of embB in natural and acquired resistance to ethambutol in mycobacteria. Antimicrob Agents Chemother. 1997;41:2270-3.

34. Plinke C, Cox HS, Zarkua N, Karimovich HA, Braker K, Diel R, RüschGerdes S, Feuerriegel S, Niemann S. embCAB sequence variation among ethambutol-resistant Mycobacterium tuberculosis isolates without embB306 mutation. J Antimicrob Chemother. 2010;65:1359-67.

\section{Submit your next manuscript to BioMed Central and we will help you at every step:}

- We accept pre-submission inquiries

- Our selector tool helps you to find the most relevant journal

- We provide round the clock customer support

- Convenient online submission

- Thorough peer review

- Inclusion in PubMed and all major indexing services

- Maximum visibility for your research

Submit your manuscript at www.biomedcentral.com/submit 